\title{
LETTERS
}

\section{Fueling the culture of distrust in physicians}

I was happy to see Dr. Dutton and colleagues add Canadian data to the literature supporting prioritization and investment in social care. ${ }^{1}$ I agree that social determinants of health can have as important an impact as health care on life expectancy - sometimes more. I also agree that using evidence to thoughtfully drive policy yields better decision-making than political agendas.

What I am disappointed by, though, is the authors' need to single out negotiations for physician funding as a lack of "shared understanding that spending on social services may also improve health outcomes." A statement like this seems totally misplaced in an otherwise wellwritten paper.

Physician services are indeed a substantial line item in health care spending but they tie for third with nursing services, behind spending on hospitals and pharmaceuticals. So why jump on physicians? Thoughtful cost savings should be sought out in all aspects of government spending.

Unfortunately, statements like this fuel the culture of distrust in physicians by playing on the politics of envy and division. Too few physicians per capita has been associated with poor population health. ${ }^{2-4}$ Health care interventions like vaccines, cataract surgeries, diabetes management and angio- plasties - physician-led endeavours have also improved life expectancy.

Balancing efficiency with equity of care should be the primary goal of all health care systems - one that we should advocate for together. Singling out physicians only detracts from the argument at hand.

\section{Nadia Alam MD}

Family physician-anesthetist, Georgetown, Ont.; president-elect, Ontario Medical Association, Toronto, Ont.

Cite as: CMAJ 2018 March 26;190:E370. doi: $10.1503 / \mathrm{cmaj} .69008$

\section{References}

1. Dutton DJ, Forest P-G, Kneebone RD, et al. Effect of provincial spending on social services and health care on health outcomes in Canada: an observational longitudinal study. CMAJ 2018; 190:E66-71.

2. Or Z. Labour market and social policy - Occasional papers no. 46. Exploring the effects of health care on mortality across OECD countries. Paris: Organisation for Economic Co-operation and Development Publishing; 2001. Available: www.oecd.-ilibrary. org/social-issues-migration-health/exploring-the -effects-of-health-care-on-mortality-across-OECD -countries_716472585704?crawler=true (accessed 2018 Mar. 12).

3. Cooper RA. States with more physicians have better-quality health care. Health Aff (Millwood) 2009;28:w91-102.

4. Piérard E. The effect of physician supply on health status: Canadian evidence. Health Policy 2014;118:56-65.

Competing interests: None declared. 